\title{
Infusion of autologous bone marrow mononuclear cells through hepatic artery results in a short-term improvement of liver function in patients with chronic liver disease: a pilot randomized controlled study
} Andre Castro Lyra ${ }^{a}$, Milena Botelho Pereira Soares ${ }^{b, c}$, Luiz Flavio Maia da Silva ${ }^{d}$, Eduardo Lorens Braga ${ }^{a}$, Sheilla A. Oliveira ${ }^{c}$, Marcos Fraga Fortes ${ }^{c}$, Andre Goyanna Pinheiro Silva ${ }^{\mathrm{e}}$, Daniele Brustolim ${ }^{\mathrm{b}}$, Bernd Genser, Ricardo Ribeiro dos Santos ${ }^{\mathrm{b}, \mathrm{c}}$ and Luiz Guilherme Costa Lyra ${ }^{\mathrm{a}}$

\begin{abstract}
Aim This randomized controlled study evaluated the effect of autologous infusion of bone marrow cells (BMC) in patients with hepatic cirrhosis.
\end{abstract}

Methods Thirty patients on the liver transplant waiting list were randomly assigned to receive BMC therapy or no treatment. They were followed up for 1 year. The study was nonblinded. Autologous mononuclear-enriched BMC were infused into the hepatic artery; liver function scores/tests were chosen as endpoints to assess efficacy. Statistical analysis calculated mean relative changes (RC) from baseline and fitted a random-effects model.

Results Mean age, baseline model for end-stage liver disease, and Child-Pugh score were similar in both groups. Child-Pugh score improved in the first 90 days in the cell therapy group compared with controls $(P=0.017$, BMC group $\mathrm{RC}=-8 \%$, controls $\mathrm{RC}=+5 \%$ ). The model for end-stage liver disease score remained stable in the treated patients (RC -2 to $+6 \%$ ), whereas it increased during follow-up in the control group (RC +6 to $+18 \%$ ). Albumin levels improved in the treatment arm, whereas they remained stable among controls in the first 90 days $(P=0.034$; $\mathrm{BMC}$ group $\mathrm{RC}=+16 \%$, control group $\mathrm{RC}=+2 \%$ ). Bilirubin levels increased among controls, whereas they decreased in the therapy arm

\section{Introduction}

Under physiological conditions, the human liver regenerates primarily through division of mature hepatocytes. When this organ is exposed to chronic insult as in viral hepatitis, the liver is repaired through the action of hepatic progenitor cells [1,2]. However, recent studies suggest that cell loss in the liver cannot be recovered exclusively through stem cells resident within the organ [3,4]. Thus, tissue damage might attract migratory stem cell populations from other organs such as the bone marrow. There is evidence that stem cells,

This study was presented in part in the Plenary Session of the 2007 Liver Meeting of the American Association for the Study of Liver Diseases (AASLD). during the first 60 days; INR RC differences between groups reached up to $10 \%$. The changes observed did not persist beyond 90 days.

Conclusion Transplantation of autologous BMC into the hepatic artery improved liver function in patients with advanced cirrhosis in the first $\mathbf{9 0}$ days. However, larger studies are necessary to define the role of BMC therapy in cirrhotic patients. Repeated autologous BMC infusions or combination therapy with granulocyte-colony-stimulating factor might improve or sustain the treatment response. Eur J Gastroenterol Hepatol 22:33-42 (c) 2010 Wolters Kluwer Health | Lippincott Williams \& Wilkins.

European Journal of Gastroenterology \& Hepatology 2010, 22:33-42

Keywords: bone marrow stem cell transplantation, $\mathrm{CD} 34^{+}$, cell therapy, chronic liver disease, cirrhosis

aHospital Sao Rafael and c-HUPES/Federal Univeristy of Bahia

Medicine-Gastro-Hepatology Service, ${ }^{b}$ Hospital Sao Rafael, Regenerative Medicine,

${ }^{\mathrm{c}}$ Fundacao Oswaldo Cruz-Ba, ${ }^{\mathrm{d}} \mathrm{Hospital}$ Sao Rafael, Medicine - Hematology,

${ }^{\mathrm{e}}$ Hospital Sao Rafael, Radiology and ${ }^{\mathrm{f}} \mathrm{BGStats}$ Consulting, Graz, Austria

Correspondence to Dr Andre Castro Lyra, MD, R Socrates Guanaes Gomes 84/401, Salvador, Bahia CEP: 40296 720, BRAZIL

Tel: + 55713235 7048; fax: + 5571 32762106; e-mail: aclyra@atarde.com.br

Received 19 March 2009 Accepted 28 May 2009

particularly those in the bone marrow, have the ability to develop into endodermal, mesodermal, and ectodermal cell types [4-7]. The extent to which bone-marrowderived cells repopulate the liver after injury, however, does not seem to be significant, and the therapeutic mechanism is not well known but could be through cell fusion and the delivery of specific substances to mature functional hepatocytes. Several studies suggest that cytokines and growth factors produced by infused bone marrow cells may support liver function and repair in adult animals without the infused cells forming new hepatocytes [7-9]. However, the specific cell types responsible for this liver regeneration process remain to be discovered. 
Several investigators have recently evaluated the therapeutic potential of bone marrow mononuclear cell (BMC) transplantation into mice with acute and chronic liver diseases. Delivery routes have varied from peripheral venous injection to direct intralobular hepatic infusion. These studies have shown reduced hepatic fibrosis and improved liver function in different animal models [10-13].

Liver transplantation is the only available therapy for patients with chronic liver failure; however, there is a shortage of donated organs. Therefore, alternative methods are necessary to increase the survival of patients on the liver transplant waiting list. Positive results for cell therapy in animal models have led us and others to evaluate the feasibility and safety of bone marrow cell therapy in patients with chronic liver disease [14-17]. These clinical studies found that BMC therapy seemed to be safe and feasible, albumin levels increased in many patients, bilirubin levels decreased, the Child-Pugh score improved, and in at least one study, the model for end-stage liver disease (MELD) score improved. Terai et al. [18] followed up nine patients treated with BMCs for up to 15 months and found persistent improvement of albumin levels and other clinical parameters. In another study, Levicar $e t$ al. [19] followed up five patients after BMC infusion and found that the beneficial effects lasted for approximately 12 months. Both these studies had no controls.

Further investigations with randomized controlled studies are necessary to evaluate the efficacy of this modality of cell therapy in patients with chronic liver disease. In this randomized pilot study, we evaluated autologous bone marrow cell therapy in cirrhotic patients on a liver transplant list.

\section{Materials and methods Patient selection}

We prospectively enrolled 30 patients with chronic liver disease who were on the waiting list for liver transplantation at the outpatient clinics of Hospital Sao Rafael, Salvador, Brazil, from January 2006 to April 2006. Written informed consent was obtained from all participants. The study protocol conformed to the ethical guidelines of the 1975 Declaration of Helsinki and was approved by the ethics committee of the institution. Eligible patients were men or women who understood the study procedures. They were also required to meet all the following inclusion criteria: age between 18 and 74 years, advanced chronic liver disease from different etiologies with indication for liver transplantation based on clinical, laboratorial, and radiological findings, absence of liver tumors, negative for human immunodeficiency virus infection, no history of malignant neoplasia except for nonmelanoma skin cancer, no history of heart failure, platelet count $\geq 30000 / \mathrm{mm}^{3}$, INR $\leq 2.4 \mathrm{IU}$, creatinine $\leq 2.5 \mathrm{mg} / \mathrm{dl}$, absence of portal vein thrombosis, no participation in other clinical trials; women could not be pregnant or lactating. Patients were excluded from the study if they were unable to be subjected to bone marrow aspiration or if they had, on the day of randomization, active hepatic encephalopathy or sepsis. Patients were randomly assigned to receive infusion of autologous BMCs or to be followed up as controls.

\section{Study design and assessments}

Potential patients underwent a medical history screening, physical examination, abdominal magnetic resonance imaging to exclude liver tumors, and laboratory tests. Thirty patients met all inclusion criteria and were moved forward to the next step, which was treatment allocation by randomization. The study was nonblinded. Baseline assessments at day 0 included complete clinical and laboratory evaluation. The first five patients randomly assigned to receive BMC therapy in the current study were also included in the analysis of a previous safety and feasibility study [16]. Laboratory tests consisted of complete blood count, serum bilirubin levels, prothrombin time, serum blood glucose, urea, creatinine, $\alpha$-fetoprotein, total proteins and albumin levels, serum aminotransferase concentrations, alkaline phosphatase and $\gamma$-glutamyl transferase levels, and thyroid-stimulating hormone concentrations. Patients were followed up for adverse events with clinical and laboratory evaluation on days $1,2,3,7,15,30,45,60$, and every month thereafter up to 360 days. Patients were subjected to abdominal ultrasound every 6 months.

\section{Therapy with bone marrow cells}

Patients in the cell therapy arm were admitted to the hospital on the previous day and subjected to $\mathrm{BMC}$ infusion in the morning. First, patients were transferred to the day-hospital operating room and sedated with sulfentanyl and ketamine by an anesthesiologist. Approximately $50 \mathrm{ml}$ of bone marrow were aspirated from the iliac crests by a hematologist. An enriched fraction of BMC was obtained by centrifugation of total bone marrow in a Ficoll-Hypaque gradient. Cell populations were analyzed by fluorescence-activated cell sorter analysis. The following antibodies from Becton Dickinson (Franklin Lakes, New Jersey, USA) were used for immunostaining: CD34FITC and CD45-APC. Three-color immunofluorescence analysis was used for identification of $\mathrm{CD} 34^{+}$population (hematopoietic progenitor cells) in BMC suspensions. The number of events acquired and analyzed for each patient was 100000 . Data acquisition and analysis were performed on a FacsCalibur device with CellQuest software (Becton Dickinson).

BMCs were prepared within approximately $2-3 \mathrm{~h}$ after bone marrow aspiration. The viability of the cells was determined by trypan blue exclusion. Mononuclearenriched BMCs suspended in $20 \mathrm{ml}$ of saline were slowly 
infused into the hepatic artery of patients over a 20-min interval with the technique routinely used for arterial chemoembolization of liver tumors [20]. Patients were discharged from the hospital the next day.

\section{Statistical analysis}

Indicators of liver function [serum albumin, bilirubin, INR (prothrombin time), Child-Pugh, and MELD scores] were chosen as endpoints to assess efficacy. We chose baseline (day 0 ) and 30,60, 90, 180, and 360 days after injection as evaluation time points. Chi-square tests (for categorical variables) and $t$-tests (for continuous variables) or Wilcoxon's tests (for ordinal variables) were used to compare patient characteristics at baseline. To determine the efficacy of cell therapy, we analyzed the data using boxplots, individual profiles of the patients, descriptive analyses of mean relative changes from baseline, and the random-effects model. Pearson's correlation was used to evaluate the correlation between the number of infused cells and the albumin levels.

Trends in liver function parameters [i.e. laboratory tests, Child-Pugh, and MELD scores] over time were explored by calculating means, standard deviations, and 95\% confidence intervals for each evaluation time point. In addition, we calculated the relative mean changes with respect to the baseline level. Finally, we fitted a randomeffects linear model to compare the response profiles of liver indicators between the treated and untreated groups. All statistical analyses were conducted using STATA statistical software (StataCorp. 2005. Stata Statistical Software: Release 8. College Station, Texas: StataCorp LP).

\section{Results}

The baseline characteristics of the patients enrolled into the study are outlined in Table 1 . Sex distribution, mean age, bilirubin and albumin levels, MELD, and ChildPugh scores were similar for both groups.

The etiology of the liver diseases encountered is described in Table 2. The majority of patients had alcoholic liver disease and/or hepatitis C. Both patients

Table 1 Patients' baseline characteristics

\begin{tabular}{|c|c|c|c|}
\hline Characteristics & Controls $(n=15)$ & Treatment arm $(n=15)$ & $P$ value \\
\hline \multicolumn{4}{|l|}{ Age (years) } \\
\hline Mean \pm SD & $50.0 \pm 10.37$ & $56.7 \pm 9.23$ & 0.075 \\
\hline \multicolumn{4}{|c|}{ Bilirubin levels (mg/dl) } \\
\hline Mean \pm SD & $2.46 \pm 1.62$ & $1.97 \pm 0.83$ & 0.312 \\
\hline \multicolumn{4}{|c|}{ Albumin levels (g/dl) } \\
\hline Mean \pm SD & $3.31 \pm 0.78$ & $2.93 \pm 0.44$ & 0.114 \\
\hline \multicolumn{4}{|c|}{ Child-Pugh score } \\
\hline Mean \pm SD & $8.47 \pm 1.60$ & $8.6 \pm 1.94$ & 0.684 \\
\hline \multicolumn{4}{|l|}{ MELD score } \\
\hline Mean \pm SD & $14.3 \pm 3.66$ & $13.3 \pm 3.44$ & 0.447 \\
\hline \multicolumn{4}{|c|}{ INR (prothrombin time) } \\
\hline Mean \pm SD & $1.48 \pm 0.27$ & $1.50 \pm 0.30$ & 0.678 \\
\hline
\end{tabular}

MELD, model for end-stage liver disease. with hepatitis B were randomly assigned to the control group. One patient was kept on lamivudine and the other on adefovir. At baseline in the BMC therapy group, one patient with mild/moderate ascites was classified as Child-Pugh A, 10 as Child-Pugh B, and four as ChildPugh C. Among controls, one patient with mild/moderate ascites was classified as Child-Pugh A, 11 as Child-Pugh $\mathrm{B}$, and three as Child-Pugh C.

Only one patient from each group was on a regular therapeutic paracentesis program with albumin replacement every 4-8 weeks, on average, before the study was initiated. Baseline albumin levels for these patients were $3.2 \mathrm{~g} / \mathrm{dl}$ (patient in control group) and $4.4 \mathrm{~g} / \mathrm{dl}$ (patient in BMC therapy group).

The mean number of bone marrow cells infused was $3.78 \times 10^{8}\left( \pm 2.69 \times 10^{8}\right)$ and the median $3.00 \times 10^{8}$ (range, $0.88 \times 10^{8}-11.2 \times 10^{8}$ ). The total number of infused cells for each patient, the etiology of the liver disease, and the age are shown in Table 2. The number of CD34 ${ }^{+}$and $\mathrm{CD} 45^{+}$cells infused was evaluated for 11 patients (Table 2). Six patients received blood products a few hours before or immediately before bone marrow aspiration and/or femoral artery catheterization because of coagulopathy and low platelet count. The type and amount of transfused blood product is shown in Table 2 .

Five patients complained of mild pain at the sites of bone marrow puncture and/or arterial puncture, and four patients developed ecchymosis/hematoma at the site of the arterial puncture that was reabsorbed a few days later. Six months after BMC infusion, one patient with cirrhosis caused by alcoholic liver disease and hepatitis $\mathrm{C}$ was diagnosed with dilated cardiomyopathy, mild heart failure, and third-degree atrioventricular block; a cardiac pacemaker was implanted and the patient recovered well.

During follow-up, three patients died in the therapy group at 6,8 , and 10 months after randomization owing to complications of chronic liver disease, whereas in the control group, two patients died at 19 days and 10 months after randomization and one patient received a liver transplant because of progressive chronic liver failure at 45 days after randomization. No patients developed liver tumors.

Of the patients who were alive during the entire period of the study, only one control patient missed the visit at day 360. His last visit was at 240 days after randomization. He was later contacted by phone. The remaining patients attended all scheduled visits.

To determine the efficacy of cell therapy, we analyzed the data using boxplots, individual profiles of the patients, descriptive analyses of mean relative changes from baseline, and the random-effects model. 
Table 2 Etiology of liver diseases of all patients and the number of infused cells and transfused blood products in the cell therapy arm

\begin{tabular}{|c|c|c|c|c|c|c|}
\hline Patient no. & Age (years) & $\begin{array}{c}\text { Etiology of liver } \\
\text { disease cell therapy arm }\end{array}$ & $\begin{array}{c}\text { Total number of cells } \\
\text { infused }\end{array}$ & $\begin{array}{l}\text { Number of CD34 }{ }^{+} \text {cells } \\
\text { infused }\end{array}$ & $\begin{array}{l}\text { Number of CD } 45^{+} \text {cells } \\
\text { infused }\end{array}$ & $\begin{array}{l}\text { Transfused blood } \\
\text { products }\end{array}$ \\
\hline 1 & 55 & Cryptogenic cirrhosis & $3.5 \times 10^{8}$ & $3.71 \times 10^{6}$ & $2.30 \times 10^{8}$ & 1 platelet apheresis \\
\hline 2 & 49 & Alcoholic liver disease & $4.8 \times 10^{8}$ & $3.46 \times 10^{6}$ & $2.81 \times 10^{8}$ & None \\
\hline 3 & 66 & Cryptogenic cirrhosis & $3.4 \times 10^{8}$ & NA & NA & None \\
\hline 4 & 41 & $\begin{array}{l}\text { Alcoholic liver disease } \\
+ \text { hepatitis C }\end{array}$ & $2.4 \times 10^{8}$ & $2.52 \times 10^{6}$ & $2.05 \times 10^{8}$ & None \\
\hline 5 & 70 & Alcoholic liver disease & $1.6 \times 10^{8}$ & $2.64 \times 10^{6}$ & $1.33 \times 10^{8}$ & None \\
\hline 6 & 49 & $\begin{array}{c}\text { Alcoholic liver disease } \\
+ \text { hepatitis C }\end{array}$ & $11.2 \times 10^{8}$ & $25.76 \times 10^{6}$ & $6.37 \times 10^{8}$ & None \\
\hline 7 & 74 & Cryptogenic cirrhosis & $2.4 \times 10^{8}$ & $3.86 \times 10^{6}$ & $1.96 \times 10^{8}$ & None \\
\hline 8 & 61 & $\begin{array}{c}\text { Alcoholic liver disease } \\
+ \text { hepatitis C }\end{array}$ & $0.88 \times 10^{8}$ & $0.77 \times 10^{6}$ & $0.70 \times 10^{8}$ & 1 platelet apheresis \\
\hline 9 & 59 & Alcoholic liver disease & $2.3 \times 10^{8}$ & $3.04 \times 10^{6}$ & $1.68 \times 10^{8}$ & None \\
\hline 10 & 50 & Hemochromatosis & $6.7 \times 10^{8}$ & $5.03 \times 10^{6}$ & $4.39 \times 10^{8}$ & 2 units of FFP \\
\hline 11 & 48 & Hepatitis C & $1.5 \times 10^{8}$ & $2.21 \times 10^{6}$ & $1.08 \times 10^{8}$ & 1 platelet apheresis \\
\hline 12 & 60 & $\begin{array}{c}\text { Alcoholic liver disease } \\
+ \text { hepatitis C }\end{array}$ & $3.0 \times 10^{8}$ & $5.10 \times 10^{6}$ & $2.03 \times 10^{8}$ & $\begin{array}{l}1 \text { platelet apheresis } \\
+8 \text { CRYO units }\end{array}$ \\
\hline 13 & 54 & Hepatitis C & $3.7 \times 10^{8}$ & NA & NA & $\begin{array}{l}1 \text { platelet apheresis } \\
+7 \text { CRYO units }\end{array}$ \\
\hline 14 & 47 & Primary biliary cirrhosis & $2.4 \times 10^{8}$ & NA & NA & None \\
\hline \multirow[t]{2}{*}{15} & 57 & Cryptogenic cirrhosis & $6.9 \times 10^{8}$ & NA & NA & None \\
\hline & & $\begin{array}{c}\text { Etiology of liver } \\
\text { disease control group }\end{array}$ & & & & \\
\hline 16 & 54 & Hepatitis C & - & - & - & - \\
\hline 17 & 50 & Alcoholic liver disease & - & - & - & - \\
\hline 18 & 37 & Alcoholic liver disease & - & - & - & - \\
\hline 19 & 64 & Alcoholic liver disease & - & - & - & - \\
\hline 20 & 58 & Alcoholic liver disease & - & - & - & - \\
\hline 21 & 50 & Cryptogenic cirrhosis & - & - & - & - \\
\hline 22 & 55 & Budd-chiari syndrome & - & - & - & - \\
\hline 23 & 54 & Hepatitis C & - & - & - & - \\
\hline 24 & 37 & Alcoholic liver disease & - & - & - & - \\
\hline 25 & 38 & $\begin{array}{c}\text { Alcoholic liver disease } \\
+ \text { hepatitis B }\end{array}$ & - & - & - & - \\
\hline 26 & 68 & $\begin{array}{c}\text { Chronic cholestatic liver } \\
\text { disease }\end{array}$ & - & - & - & - \\
\hline 27 & 32 & Hepatitis B & - & - & - & - \\
\hline 28 & 46 & $\begin{array}{c}\text { Alcoholic liver disease } \\
+ \text { hepatitis C }\end{array}$ & - & - & - & - \\
\hline 29 & 53 & Hepatitis C & - & - & - & - \\
\hline 30 & 46 & $\begin{array}{c}\text { Alcoholic liver disease } \\
+ \text { hepatitis C }\end{array}$ & - & - & - & - \\
\hline
\end{tabular}

CRYO, cryoprecipitate; FFP, fresh frozen plasma; NA, not available.

Analysis of the Child-Pugh score over the first 3 months revealed a mild increase in the control group and a significant decrease in the treatment group. The ChildPugh score improved in the therapy arm, particularly during the first 90 days after BMC therapy; this effect is clearly demonstrated by the boxplots as well as the mean relative changes from baseline, where the difference between groups reached $14 \%$ in the first 30 days (Fig. 1) (Table 3). Slopes obtained from the random-effects model were significantly different between the two groups $(P=0.017)$ (Table 4$)$. At 12 months, there was a slight (nonsignificant) increase in the control group.

The MELD score significantly increased during the 12 months of follow-up in the control group $(P=0.014)$; this increase was greatest in the first 3 months $(P=0.009) \quad$ (Table 4$)$. In the treated patients, the MELD score remained stable. However, the difference between the slopes of the two groups did not reach statistical significance at 3 months $(P=0.085)$ or 12 months $(P=0.189)$ (Table 4$)$. Boxplots of the MELD score also showed slight improvement after BMC therapy (Fig. 2). Evaluation of the mean relative changes from baseline reveal that the MELD score stabilized in the cell therapy group but increased in the control group; the difference between groups reached $14 \%$ after 60 days (Table 3 ).

Albumin levels increased significantly after BMC therapy, particularly in the first 90 days (Fig. 3); mean levels had increased by up to $16 \%$ at 90 days as compared with baseline levels (Table 3). In the control group, albumin levels decreased slightly during follow-up. The randomeffects model showed that serum albumin levels at 3 months were significantly increased in the interven tion group $(0.14 \mathrm{~g} / \mathrm{dl}$ per 30 days; $P=0.001)$, whereas they did not change in the control group (Table 4). The difference between the slopes of the two groups was statistically significant $(P=0.034)$. This difference had diminished at 12 months. 


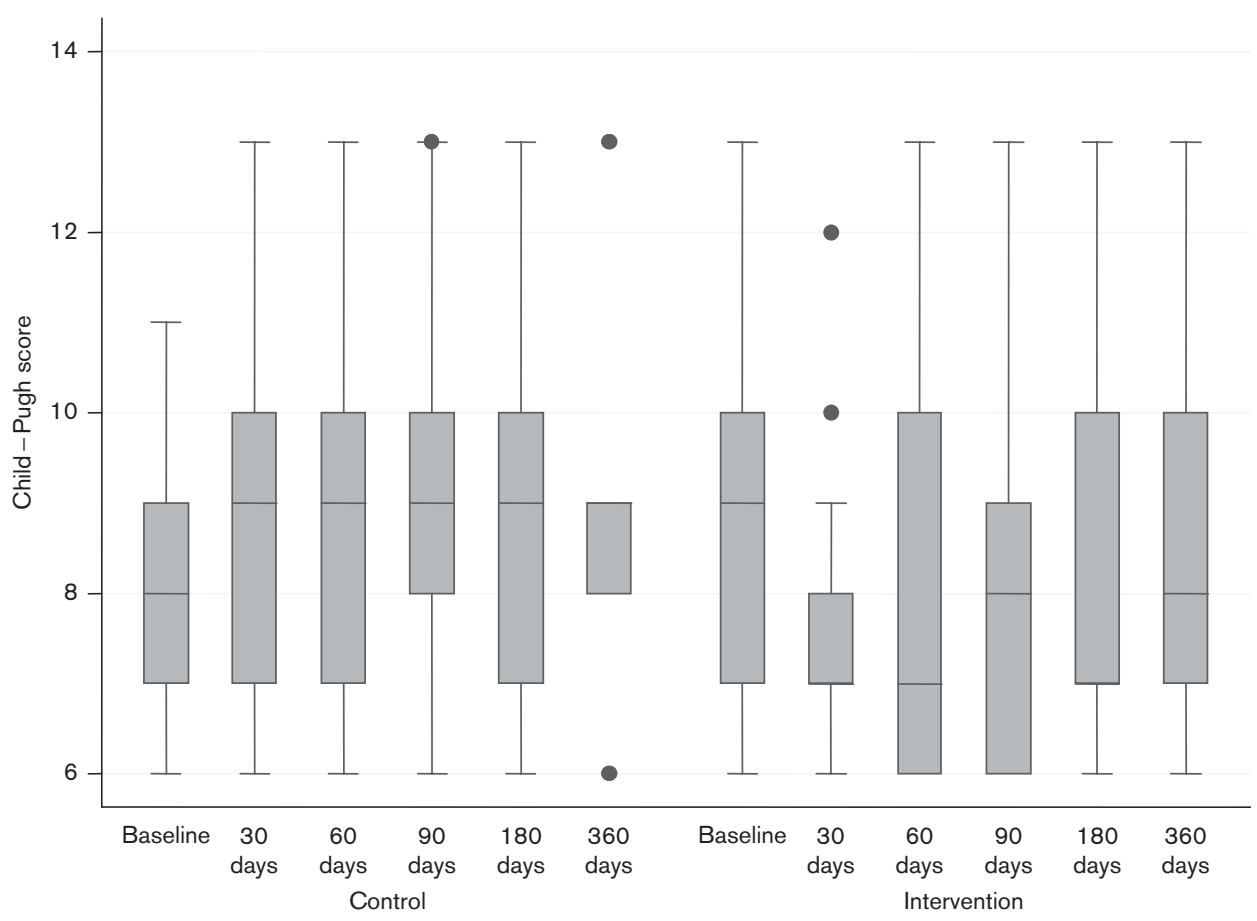

Boxplots of Child-Pugh scores and individual Child-Pugh scores from controls and patients of the intervention (bone marrow mononuclear cell therapy) group and their respective time points.

Table 3 Descriptive analysis of Child-Pugh and MELD scores, albumin levels, bilirubin, and INR (prothrombin time) levels in both the study groups during follow-up

\begin{tabular}{|c|c|c|c|}
\hline Time point & Control (\%) & Intervention (\%) & Difference (\%) \\
\hline \multicolumn{4}{|c|}{ Mean relative change from baseline Child-Pugh score } \\
\hline 30 days & 2 & -11 & -13 \\
\hline 60 days & 5 & -7 & -12 \\
\hline 90 days & 5 & -8 & -13 \\
\hline 180 days & 6 & -6 & -12 \\
\hline 360 days & 5 & -2 & -7 \\
\hline \multicolumn{4}{|c|}{ Mean relative change from baseline MELD score } \\
\hline 30 days & 7 & 0 & -7 \\
\hline 60 days & 12 & -2 & -14 \\
\hline 90 days & 13 & 2 & -11 \\
\hline 180 days & 6 & -3 & -9 \\
\hline 360 days & 18 & 6 & -12 \\
\hline \multicolumn{4}{|c|}{ Mean relative change from baseline of albumin levels } \\
\hline 30 days & -2 & 14 & 16 \\
\hline 60 days & -6 & 14 & 20 \\
\hline 90 days & 2 & 16 & 14 \\
\hline 180 days & -2 & 11 & 13 \\
\hline 360 days & -2 & 12 & 14 \\
\hline \multicolumn{4}{|c|}{ Mean relative change from baseline of bilirubin levels } \\
\hline 30 days & 123 & 4 & -120 \\
\hline 60 days & 302 & -5 & -307 \\
\hline 90 days & 179 & 1 & -178 \\
\hline 180 days & 182 & 10 & -172 \\
\hline 360 days & 177 & 39 & -138 \\
\hline \multicolumn{4}{|c|}{ Mean relative change from baseline of INR (prothrombin time) levels } \\
\hline 30 days & 1 & -1 & -2 \\
\hline 60 days & 9 & -1 & -10 \\
\hline 90 days & 7 & 1 & -6 \\
\hline 180 days & 1 & -4 & -5 \\
\hline 360 days & 9 & 1 & -8 \\
\hline
\end{tabular}

MELD, model for end-stage liver disease.
To rule out the possibility that albumin levels could have been influenced by blood product transfusion, we compared the albumin levels of the six patients who received blood products during BMC therapy with those of nine patients who did not receive blood products. Albumin levels were similar in both of these subgroups at baseline $(P=0.74)$ and after BMC therapy $(P=0.68$ at 30 days, $P=0.83$ at 60 days and $P=0.73$ at 90 days) (Table 5).

Of note, there was no correlation between the total number of cells infused, the number of CD $34^{+}$cells, and the number of $\mathrm{CD} 45^{+}$cells infused and the albumin levels (data not shown).

Total bilirubin levels of patients in the therapy arm were lower than baseline, especially in the first 2 months after BMC infusion (Fig. 4). Analysis of mean relative changes from baseline revealed stabilized bilirubin levels during the first 90 days after BMC therapy, whereas bilirubin levels were increased at all follow-up time points in controls (Table 3). The random-effects model showed that bilirubin levels increased significantly during the 12 months of follow-up in the control group $(P=0.011)$, whereas it remained unchanged in the treated patients. Despite this, the differences between the two slopes did not reach statistical significance at 3 months $(P=0.099)$ 
Table 4 Results from the random effects model at 90 and 360 days

\begin{tabular}{|c|c|c|c|c|}
\hline & 90 Days & Coefficient & 95\% Confidence interval & $P$ value \\
\hline \multirow[t]{3}{*}{ CP score } & Slope in control group & 0.120 & $(-1.140$ to 1.540$)$ & 0.185 \\
\hline & Slope in BMC group & -0.187 & $(-0.364$ to -0.009$)$ & 0.039 \\
\hline & Comparison of slopes & -0.307 & $(-0.558$ to -0.056$)$ & 0.017 \\
\hline \multirow[t]{3}{*}{ MELD score } & Slope of control group & 0.633 & (0.157 to 1.110$)$ & 0.009 \\
\hline & Slope of BMC group & 0.040 & $(-0.437$ to 0.517$)$ & 0.869 \\
\hline & Comparison of slopes & -0.593 & $(-1.268$ to 0.081$)$ & 0.085 \\
\hline \multirow[t]{3}{*}{ Albumin } & Slope of control group & 0.011 & $(-0.072$ to 0.095$)$ & 0.790 \\
\hline & Slope of BMC group & 0.139 & $(-0.056$ to 0.223$)$ & 0.001 \\
\hline & Comparison of slopes & 0.128 & (0.010 to 0.246$)$ & 0.034 \\
\hline \multirow[t]{3}{*}{ Bilirubin } & Slope of control group & 1.460 & (0.222 to 2.698$)$ & 0.021 \\
\hline & Slope of BMC group & -0.015 & $(-1.253$ to 1.222$)$ & 0.981 \\
\hline & Comparison of slopes & -1.475 & $(-3.225$ to 0.275$)$ & 0.099 \\
\hline \multirow[t]{4}{*}{ INR (prothrombin time) } & Slope of control group & 0.040 & $(-0.0004$ to 0.080$)$ & 0.052 \\
\hline & Slope of BMC group & 0.004 & $(-0.036$ to 0.044$)$ & 0.851 \\
\hline & Comparison of slopes & -0.036 & $(-0.093$ to 0.021$)$ & 0.215 \\
\hline & 360 days & & & \\
\hline \multirow[t]{3}{*}{ CP score } & Slope of control group & 0.076 & $(-0.025$ to 0.177$)$ & 0.140 \\
\hline & Slope of BMC group & 0.010 & (0.092 to 0.110$)$ & 0.854 \\
\hline & Comparison of slopes & -0.067 & $(-0.210$ to 0.076$)$ & 0.361 \\
\hline \multirow[t]{3}{*}{ Meld score } & Slope of control group & 0.345 & $(0.070$ to 0.620$)$ & 0.014 \\
\hline & Slope of BMC group & 0.084 & $(-0.191$ to 0.359$)$ & 0.551 \\
\hline & Comparison of slopes & -0.261 & $(-0.650$ to 0.128$)$ & 0.189 \\
\hline \multirow[t]{3}{*}{ Albumin } & Slope of control group & -0.002 & $(-0.049$ to 0.045$)$ & 0.936 \\
\hline & Slope of BMC group & 0.047 & $(-0.0002$ to 0.094$)$ & 0.051 \\
\hline & Comparison of slopes & 0.049 & $(-0.0177$ to 0.115$)$ & 0.151 \\
\hline \multirow[t]{3}{*}{ Bilirubin } & Slope of control group & 0.747 & (0.169 to 1.325$)$ & 0.011 \\
\hline & Slope of BMC group & -0.015 & $(-1.253$ to 1.223$)$ & 0.677 \\
\hline & Comparison of slopes & -0.624 & $(-1.44$ to 0.193$)$ & 0.134 \\
\hline \multirow[t]{3}{*}{ INR (prothrombin time) } & Slope of control group & 0.017 & $(-0.003$ to 0.037$)$ & 0.102 \\
\hline & Slope of BMC group & 0.0006 & $(-0.020$ to 0.021$)$ & 0.955 \\
\hline & Comparison of slopes & -0.016 & $(-0.045$ to 0.012$)$ & 0.265 \\
\hline
\end{tabular}

CP, Child-Pugh; MELD, model for end-stage liver disease.

Fig. 2

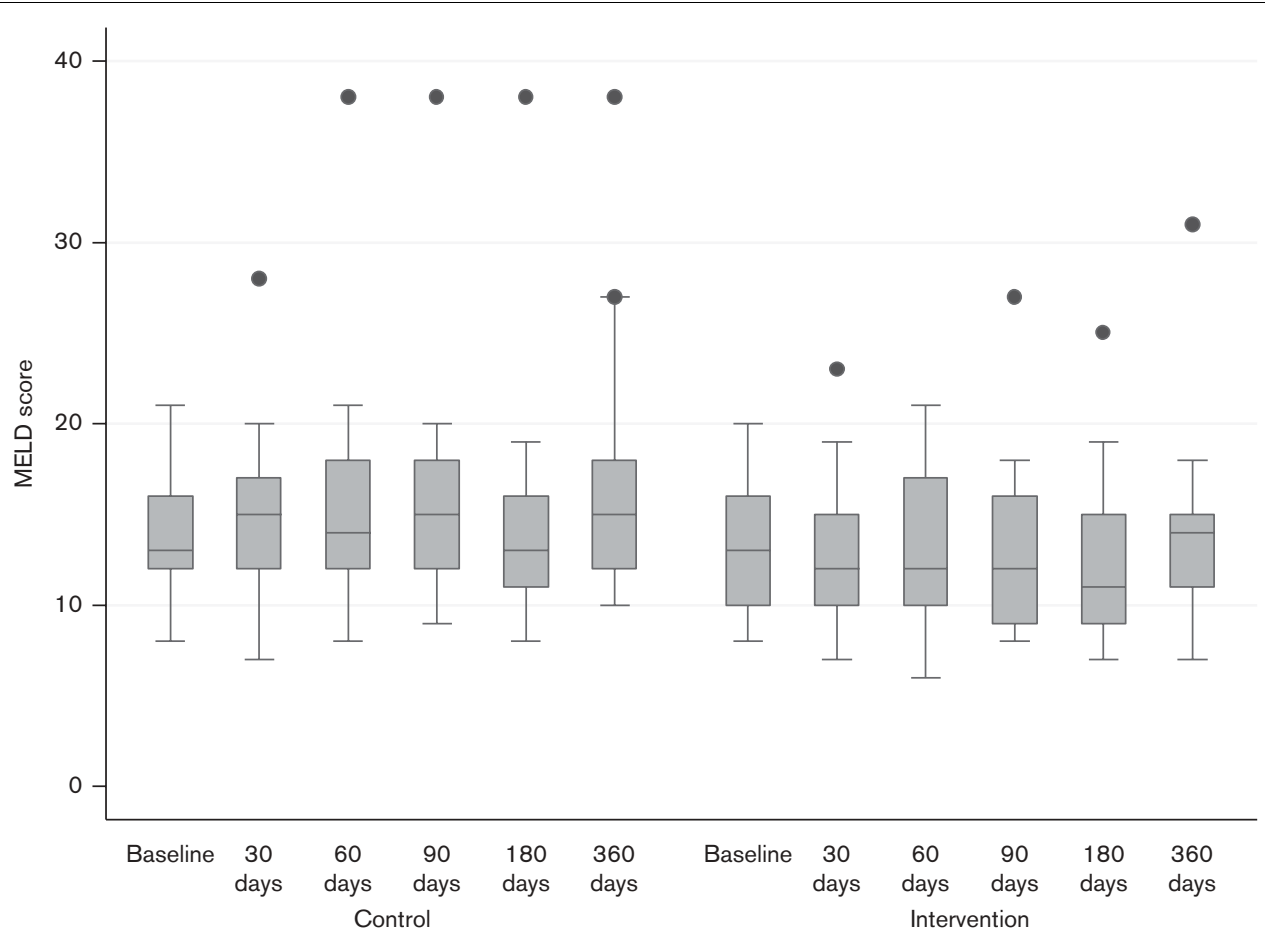

Boxplots and individual model for end-stage liver disease (MELD) scores of controls and patients of the intervention group at the evaluated time points. 


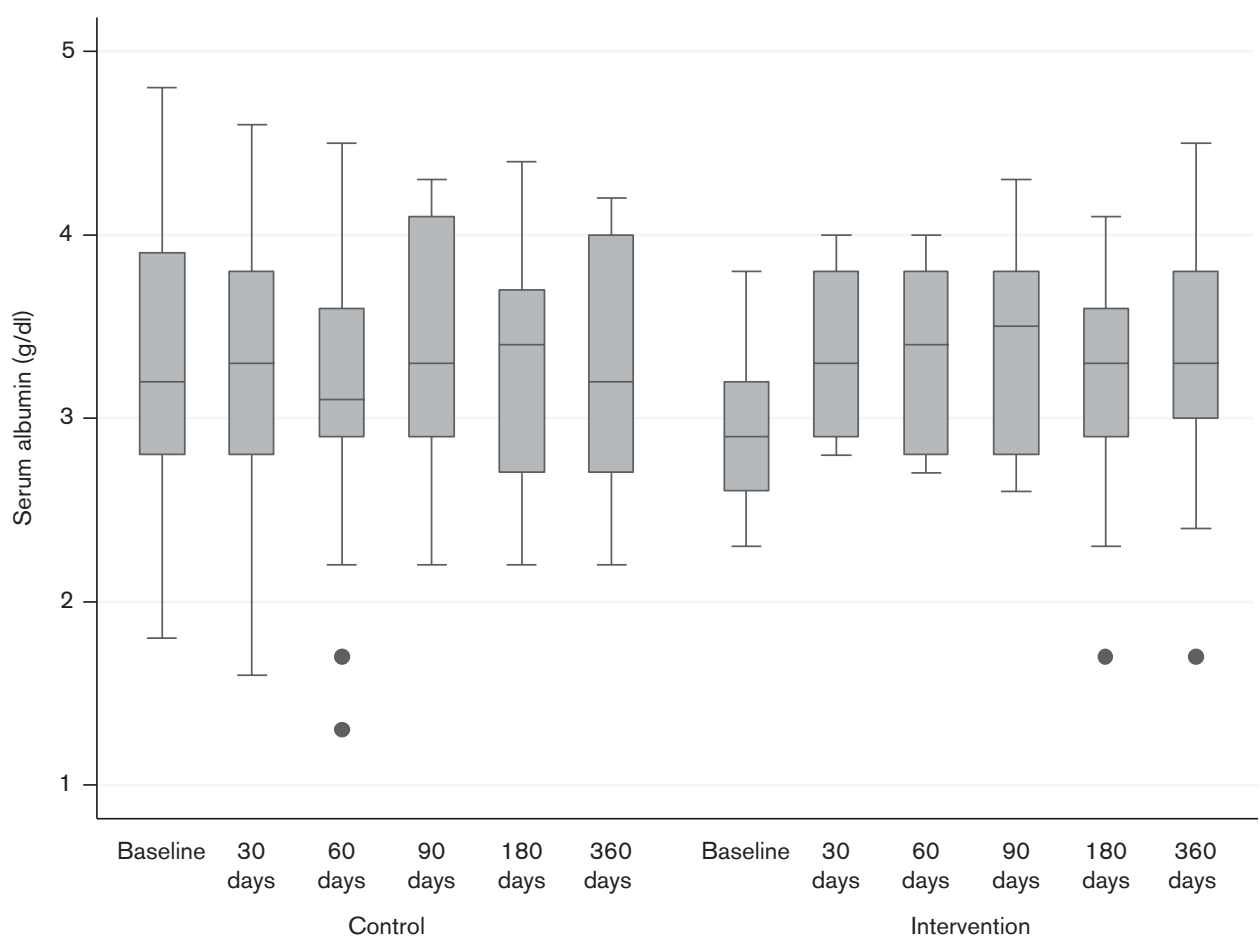

Boxplot analysis of albumin levels and individual albumin levels from controls and patients subjected to bone marrow mononuclear cell therapy.

Table 5 Comparison between albumin levels among patients who received blood products (subgroup 1) and patients who did not receive blood products during BMC therapy (subgroup 2)

\begin{tabular}{lcc}
\hline $\begin{array}{c}\text { Mean albumin level } \pm \text { SD } \\
\text { subgroup 1 }(n=6)\end{array}$ & $\begin{array}{c}\text { Mean albumin level } \pm \text { SD } \\
\text { subgroup 2 }(n=9)\end{array}$ & $P$ value \\
\hline Baseline & $\begin{array}{c}\text { Baseline } \\
2.83 \pm 0.40\end{array}$ & 0.74 \\
30 days after BMC & $\begin{array}{c}2.98 \text { days after BMC } \\
3.28 \pm 0.42\end{array}$ & 0.68 \\
60 days after BMC & $\begin{array}{c}60 \text { days after BMC } \\
3.20 \pm 0.52\end{array}$ & \\
90 days after BMC & $\begin{array}{c}3.46 \pm 0.48 \\
\text { days after BMC } \\
3.28 \pm 0.54\end{array}$ & 0.83 \\
\hline
\end{tabular}

BMC, bone marrow mononuclear cell.

or 12 months $(P=0.134)$ (Table 4$)$. Analysis of mean relative INR (prothrombin time) changes from baseline is shown in Table 3.

There were no significant differences between groups for other relevant laboratory parameters (white blood cells, hemoglobin, aspartate aminotransferase, alanine aminotransferase, $\gamma$-glutamyl transferase, and creatinine; data not shown).

\section{Discussion}

This is the first pilot randomized, controlled study to evaluate the efficacy of autologous BMC transplantation in patients with advanced chronic liver disease. We found a potential beneficial effect of this modality of cell therapy in the studied population; the Child-Pugh score improved, the MELD score and bilirubin levels stabilized, and albumin levels increased in the treated arm. The Child-Pugh score measures five variables, two of which (encephalopathy and ascites) are subjective; the fact that this study was not blinded might have influenced the evaluation of this score to some extent. Nevertheless, all other analyzed parameters were objective; the combination of results therefore suggests a beneficial effect for BMC-treated patients. It is notable that there were more patients with alcoholic liver disease in the control group, and that both patients with hepatitis $\mathrm{B}$ who were kept on lamivudine treatment were also assigned to the control group. Decompensated alcoholic cirrhosis might improve in some patients after they quit drinking, and occasionally patients with hepatitis B improve after drug therapy and are withdrawn from the liver transplant waiting list. If this happened in the present study, it would favor the control arm. In addition, only one patient from each group was on regular therapeutic paracentesis with albumin replacement, and blood product transfusion did not seem to influence albumin levels (Table 3). Therefore, the difference detected in albumin levels between groups was not related to albumin infusion or blood component transfusion.

The improvement of liver function detected in our study was partial and primarily occurred in the first 3 months after BMC therapy. Beyond this period, liver function 


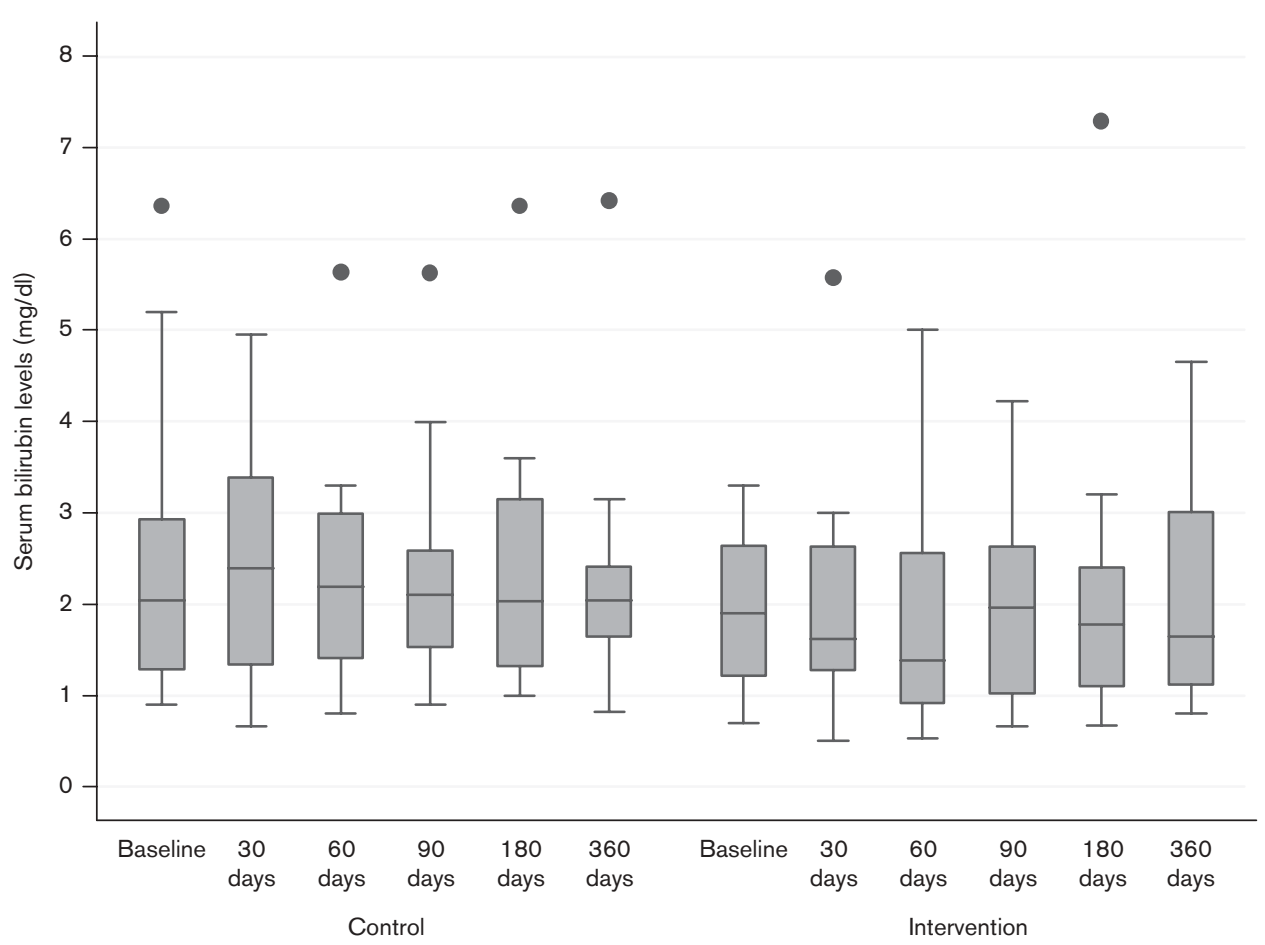

Boxplot analysis and individual slopes of bilirubin levels from the control and intervention groups and their respective time points.

seemed to return to baseline levels. The mechanisms underlying the improvement of liver function after infusion of mononuclear cells are not well understood; in addition, the cell types responsible for the observed hepatoprotective and putative regenerative effects remain to be determined. The pattern of response observed in our patients favors the hypothesis that BMC therapy benefits the liver through delivery of specific substances to mature functional hepatocytes rather than through transdifferentiation. As such, it is logical to expect that the duration of action of these substances should be temporary, as most infused mononuclear cells would not permanently reside in the liver. Several studies suggest that cytokines and growth factors produced by infused bone marrow cells may improve liver function and cause tissue regeneration in adult animals without formation of new hepatocytes from infused cells $[7,8]$.

Mouse models of liver diseases have also shown decreased hepatic fibrosis after BMC infusion. We did not subject our patients from both groups to liver biopsies to evaluate the histological effects of this therapy because we thought this might be considered unethical. We were concerned about the development of complications after such an invasive procedure, even through transjugular access, especially considering that we were testing a new and perhaps still controversial therapeutic option. The development of complications might have prematurely jeopardized the analysis of this modality of therapy.
Our study did not show survival improvement, which is the ultimate goal of any therapy. Nevertheless, it should be noted that this is the first study to evaluate the efficacy of this new potential treatment for patients with decompensated cirrhosis; thus, future studies may tailor the treatment conditions to achieve the maximum therapeutic effect. In this regard, it is likely that repeated infusions of cells might be necessary to generate a greater beneficial effect. It is also important to evaluate adjuvant therapies such as injection of granulocyte-colony-stimulating factor (G-CSF) to mobilize BMCs. Gaia et al. [14] evaluated the feasibility and safety of BMC mobilization in eight patients with end-stage liver cirrhosis after G-CSF administration. Mobilization of bone marrow cells (monitored by the number of $\mathrm{CD}_{3} 4^{+}$cells) was observed in all patients after G-CSF administration, which was well tolerated and free of adverse events. The Child-Pugh score decreased by 2 or more points in four patients, increased in one patient, and was unchanged (or decreased by less than 2 points) in three patients. Overall, the MELD score decreased from a median pretreatment value of 17.5 (range 11-20) to 14.5 (range 9-20) at the end of follow-up.

Some investigators have found that a significant proportion of myofibroblasts are of bone marrow origin in human liver fibrosis; concerns have thus been raised regarding bone marrow cell therapy in patients with hepatic 
cirrhosis $[6,7,21]$. We, however, did not detect deterioration of liver function after BMC treatment, nor did we detect the development of hepatocellular carcinoma.

Another unresolved issue is the ideal administration route for BMCs. We chose infusion into the hepatic artery, because this technique is routinely used for arterial chemoembolization of liver tumors, and it is feasible and not associated with serious local side-effects [18]. In addition, the blood influx to the liver is mostly secured using the hepatic artery as the vascular access for cell infusion. For ethical reasons, we opted not to perform bone marrow aspiration and sham intrahepatic injections in our control group. It is worth mentioning that studies in animal models and in patients with cirrhosis have evaluated the infusion of BMCs using the peripheral vein with satisfactory results [17]. Thus, the best way to administer this therapy still remains to be defined.

We did not detect any major side-effects in the first month after BMC therapy. One patient developed thirddegree atrioventricular block, mild heart failure and was implanted with a cardiac pacemaker at 6 months after therapy. In the authors' opinion, this event most probably was not related to BMC infusion. Intracoronary injection of mononuclear bone marrow cells in individuals with cardiac diseases has been evaluated in larger studies and has not been associated with a higher number of adverse events as compared with controls. In fact, several of these studies were associated with improved cardiac function and lower mortality [22-26]. In addition, in our study, the adverse event occurred at 6 months after BMC therapy; this was after the 3 -month period of maximum benefit produced by the cell treatment.

In summary, this pilot randomized controlled study showed beneficial effects of autologous BMC transplantation on liver function for up to 90 days in patients with advanced chronic liver disease. Repeated autologous BMCs infusions or the association of cell therapy with G-CSF might be a promising treatment option for patients with advanced chronic liver disease. However, larger randomized, controlled, and double-blinded studies are necessary to define the role of BMC therapy in patients with liver disease and to determine new protocols to prolong the therapeutic effects $[21,27]$.

\section{Acknowledgements}

The authors are indebted to Professor Luigi Verze, Andrea Garziera, Laura Ziller, Liliana Ronzoni for their invaluable support, to Patricia S Brandao, Heleni Carvalho, Andrea S. Sant'Ana, Gabriela Fortes, Paulo Engracio Souza, and Wilson Carvalho for their assistance in the care of patients and to Carol Coelho, Amanda Mascarenhas and Carlos Daniel Carvalho for their support in the organization of the clinical data.
The authors thank Dr John R. David for careful review of the manuscript.

Author contributions: Andre Castro Lyra, Milena Botelho Pereira Soares, Ricardo Ribeiro dos Santos and Luiz Guilherme Costa Lyra designed the study; Andre Castro Lyra, Milena Botelho Pereira Soares, Luiz Flavio Maia da Silva, Eduardo Lorens Braga, Sheilla A. Oliveira, Marcos Fraga Fortes, Andre Goyanna Pinheiro Silva, Daniele Brustolim, Ricardo Ribeiro dos Santos, Luiz Guilherme Costa Lyra conducted the study; Andre Castro Lyra, Milena Botelho Pereira Soares, Ricardo Ribeiro dos Santos, Luiz Guilherme Costa Lyra and Bernd Genser analyzed the data; Andre Castro Lyra, Milena Botelho Pereira Soares, Ricardo Ribeiro dos Santos and Luiz Guilherme Costa Lyra wrote the paper. This study was supported in part by Fundacao Monte Tabor-Brazil and Instituto do Milenio. No conflicts of interest exist.

\section{References}

1 Evarts RP, Nagy P, Nakatsukasa H, Marsden E, Thorgeirsson SS. In vivo differentiation of rat liver oval cells into hepatocytes. Cancer Res 1989; 49:1541-1547.

2 Tatematsu M, Ho RH, Kaku T, Ekem JK, Farber E. Studies on the proliferation and fate of oval cells in the liver of rats treated with 2-acetylaminofluorene and partial hepatectomy. Am J Pathol 1984; 114:418-430.

3 Theise ND, Badve S, Saxena R, Henegariu O, Sell S, Crawford JM, et al. Derivation of hepatocytes from bone marrow cells in mice after radiation-induced myoablation. Hepatology 2000; 31:235-240.

4 Lagasse E, Connors H, Al-Dhalimy M, Reitsma M, Dohse M, Osborne L, et al. Purified hematopoietic stem cells can differentiate into hepatocytes in vivo. Nature Med 2000; 6:1229-1234.

5 Lévesque JP, Winkler IG, Larsen SR, Rasko JE. Mobilization of bone marrow-derived progenitors. Handb Exp Pharmacol 2007; 180:3-36.

6 Forbes SJ, Russo FP, Rey V, Burra P, Rugge M, Wright NW, et al. A significant proportion of myofibroblasts are of bone marrow origin in human liver fibrosis. Gastroenterology 2004; 126:955-963.

7 Kallis YN, Alison MR, Forbes SJ. Bone marrow stem cells and liver disease. Gut 2007; 56:716-724.

8 Thorgeirsson SS, Grisham JW. Hematopoietic cells as hepatocyte stem cells: a critical review of the evidence. Hepatology 2006; 43:2-8.

9 Yannaki E, Athanasiou E, Xagorari A, Constantinou V, Batsis I, Kaloyannidis P, et al. G-CSF-primed hematopoietic stem cells or G-CSF per se acelerate recovery and improve survival after liver injury, predominantly by promoting endogenous repair programs. Exp Hematol 2005; 35:108-119.

10 Fang B, Shi M, Liao L, Yang S, Liu Y, Zhao RC. Systemic infusion of $\operatorname{FLK} 1(+)$ mesenchymal stem cells ameliorate carbon tetrachloride-induced liver fibrosis in mice. Transplantation 2004; 78:83-88.

11 Sakaida I, Terai S, Nishina H, Okita K. Development of cell therapy using autologous bone marrow cells for liver cirrhosis. Med Mol Morphol 2005; 38:197-202.

12 Sakaida I, Terai S, Yamamoto N, Aoyama K, Ishikawa T, Nishina H, Okita K. Transplantation of bone marrow cells reduces $\mathrm{CCl} 4$-induced liver fi brosis in mice. Hepatology 2004; 40:1304-1311.

13 Allen KJ, Cheah DMY, Lee XL, Pettigrew-Buck NE, Vadolas J, Mercer JFB, et al. The potential of bone marrow stem cells to correct liver dysfunction in a mouse model of Wilson's disease. Cell Transplant 2004; 13:765-773.

14 Gaia S, Smedile A, Omede P, Olivero A, Sanavio F, Balzola F, et al. Feasibility and safety of G-CSF administration to induce bone marrow-derived cells mobilization in patients with end stage liver disease. J Hepatol 2006; 45:13-19.

15 Gordon MY, Levicar N, Pai M, Bachellier P, Dimarakis I, Al-Allaf F, et al. Characterization and clinical application of human CD34 + stem/progenitor cell populations mobilized into the blood by granulocyte colonystimulating factor. Stem Cells 2006; 24:1822-1830.

16 Lyra AC, Soares MB, da Silva LF, Fortes MF, Silva AG, Mota AC, et al. Feasibility and safety of autologous bone marrow mononuclear cell 
transplantation in patients with advanced chronic liver disease. World J Gastroenterol 2007; 13:1067-1073.

17 Terai S, Ishikawa T, Omori K, Aoyama K, Marumoto Y, Urata Y, et al. Improved liver function in patients with liver cirrhosis after autologous bone marrow cell infusion therapy. Stem Cells 2006; 24:2292-2298.

18 Terai S, Segawa M, Omori K, Takuya I, Mizunaga Y, Matsumoto T, et al. Long time follow up for the patient of autologous bone marrow cell infusion (ABMI) therapy for liver cirrhosis. Hepatology 2007;

46 (Suppl 1):246A.

19 Levicar N, Pai M, Habib NA, Tait P, Jiao LR, Marley SB, et al. Long-term clinical results of autologous infusion of mobilized adult bone marrow derived CD34 + cells in patients with chronic liver disease. Cell Prolif 2008; 41 (Suppl 1):115-125.

20 Ahrar K, Gupta S. Hepatic artery embolization for hepatocellular carcinoma: technique, patient selection, and outcomes. Surg Oncol Clin N Am 2003; 12:105-126.

21 Houlihan DD, Newsome PN. Critical review of clinical trials of bone marrow stem cells in liver disease. Gastroenterology 2008; 135:438-450.

22 Lunde K, Solheim S, Aakhus S, Arnesen H, Abdelnoor M, Egeland T, et al. Intracoronary injection of mononuclear bone marrow cells in acute myocardial infarction. N Engl J Med 2006; 355:1199-1209.
23 Schächinger V, Erbs S, Elsässer A, Haberbosch W, Hambrecht R, Hölschermann $\mathrm{H}$, et al. Intracoronary bone marrow-derived progenitor cells in acute myocardial infarction. $N$ Engl J Med 2006; 355:1210-1221.

24 Assmus B, Fischer-Rasokat U, Honold J, Seeger FH, Fichtlscherer S, Tonn T, et al. Transcoronary transplantation of functionally competent BMCs is associated with a decrease in natriuretic peptide serum levels and improved survival of patients with chronic postinfarction heart failure: results of the TOPCARE-CHD Registry. Circ Res 2007; 100:1234-1241.

25 Lunde K, Solheim S, Aakhus S, Arnesen H, Moum T, Abdelnoor M, et al. Exercise capacity and quality of life after intracoronary injection of autologous mononuclear bone marrow cells in acute myocardial infarction: results from the Autologous Stem cell Transplantation in Acute Myocardial Infarction (ASTAMI) randomized controlled trial. Am Heart J 2007; 154:710.e1-710.e8.

26 Vilas-Boas F, Feitosa GS, Soares MB, Pinho-Filho JA, Mota A, Almeida AJ, et al. Bone marrow cell transplantation to the myocardium of a patient with heart failure due to Chagas' disease. Arq Bras Cardiol 2004; 82:185-187.

27 Lyra AC, Soares MB, dos Santos RR, Lyra LG. Bone marrow stem cells and liver disease. Gut 2007; 56:1640. 